\title{
Viewpoint: Animal-Unit Equivalents Should Be Weighted by Dietary Differences
}

\section{N. THOMPSON HOBBS AND LEN H. CARPENTER}

Scarnecchia (1985) recently reviewed the animal-unit and animalunit-equivalent concept in range science. Here, we take exception to two major points in that review. We argue that an animal-unit must be defined in terms of intake of a specific animal type and, given such a definition, that animal-unit equivalents should be weighted by approximations of dietary overlap. We submit that knowledge of dietary overlap (forage mix) between herbivores is essential to calculating the amount of a forage type or plant species that will be removed from a specific area when that area is stocked with a certain level and mix of herbivores.

The Society for Range Management (1974) defined an animalunit as a mature 454-kg cow with an associated forage intake of 12 $\mathrm{kg}$ dry matter/day. This definition has two important components: an animal (mature cow) and its intake (12 kg/day). Scarnecchia and Kothmann (1982) "simplified" the definition by removing the animal component and redefining the animal-unit ". . . as a unit of animal demand equal to $12 \mathrm{~kg}$ per day"(Scarnecchia 1985:347). We argue that if the animal-unit is not defined with respect to a specific animal type, it can be dispensed with altogether. After all, kilograms work quite well as a unit of animal demand and need not be arbitrarily multiplied by 12 to enhance their utility in that role. Our point is that an animal-unit is meaningless unless defined in reference to a specific grazing animal.

The fundamental utility of the animal-unit concept is its use in estimating impacts of animals on rangeland in terms of stocking rate. Animal-unit equivalents are used to approximate the number of individuals of a given animal type that impact the range in the same way as does a single cow. For example, if seven deer have the same impact as one cow, then the animal-unit equivalent for deer = 7. Animal-unit equivalents are widely used in this way to facilitate decisions on forage allocation among sympatric herbivores (Eastman 1982) or to calculate compensation for game damage on privately owned rangeland. Scarnecchia (1985) argued that animalunit equivalents should not be used for interspecific comparisons. However, we suspect that interspecific comparisons of grazing animals will continue to be used in policy decisions. We reply that whenever animal-unit equivalents are used to compare species, they should be weighted by dietary differences. We agree that given the complexities of diet selection by herbivores, such weighting certainly fails to yield the final answer to the question of relative impacts of different herbivores on vegetation. But it is also true that an enormous investment in the study of herbivore food habits (reviewed by Kufeld 1973, Kufeld et al. 1973, Van Dyne et al. 1980)

Authors are wildlife researcher and wildlife research leader, Colorado Division of Wildlife, 317 W. Prospect, Fort Collins 80526. Manuscript accepted 28 July 1986. suggests such weighting yields an answer much closer to the truth than the unweighted estimates advocated by Scarnecchia (1985). This is the case because different animals consistently eat different plants and, as a result, have different impacts on rangeland.

Scarnecchia (1985:348) argued that dietary differences should not be used to adjust animal-unit equivalents because such adjustment incorporates "an herbage related factor." Indeed, diet selection is influenced by herbage availability, as is dry matter intake. However, diet selection, like dry matter intake, has a strong physiological and anatomical basis (Hoffman 1973, Janis 1976, Kay et al. 1980, Hanley 1982). It follows that the food choices of animals be conceptualized in the same way that Scarnecchia (1985: Fig. 2) partitions environmental and animal influences on intake. Thus, we contend that animal food habits and, consequently, dietary overlap, do not fail outside the conceptual boundaries of the animal-unit concept.

We do not believe that removing the animal basis for the definition of the animal-unit improves its clarity or its utility. Given that an animal-unit is defined in terms of a specific animal species, then interspecific differences in food habits should be incorporated in calculations of animal-unit equivalents whenever they are used for comparing relative impacts of herbivores on rangelands.

\section{Literature Cited}

Eastman, D.L. 1982. Development of quantified elk and deer management objectives in Oregon for natural resources allocation planning. Proc. West. Ass. Fish Wildl. Agencies 62:130-137.

Hanley, T.A. 1982. The nutritional basis for food selection by ungulates. J. Range Manage. 33:146-151.

Hoffman, R.R. 1973. The ruminant stomach. E. Afr. Monogr. in Biol. 2. E. Afr. Lit. Bur. Nairobi, Kenya.

Janis, C. 1976. The evolutionary strategy of the Equidae and the origins of rumen and cecal digestion. Evolution 30:757-774.

Kay, R.N.B., W.V. Engelhardt, and R.G. White. 1980. The digestive physiology of wild ruminants. p. 743-761 In: Ruckebusch and $P$. Thivend, eds. Digestive Physiology and Metabolism in Ruminants. AVI, Westport, Conn.

Kufeld, R.C. 1973. Foods eaten by the Rocky Mountain elk. J. Range Manage. 26:106-113.

Kufeld, R.C., O.C. Wallmo, and C. Feddema. 1973. Foods of the Rocky Mountain mule deer. USDA Forest Serv. Res. Pap. RM-111.

Mackie, R.J. 1970. Range ecology. Range ecology and relations of mule deer, elk, and cattle in the Missouri River Breaks, Montana. Wildl. Monog. 20.

Scarnecchia, D.L. 1985. The animal-unit and animal-unit-equivalent concepts in range science. J. Range Manage. 38:346-349.

Scarnecchia, D.L., and M.M. Kothmann. 1982. A dynamic approach to grazing management terminology. J. Range Manage. 35:266-264.

Society for Range Management. 1974. A glossary of terms used in range management. 2nd Ed. Denver, Colo.

Van Dyne, G.M., N.R. Brockington, Z. Szocs, J. Duek, and C.A. Ribic. 1980. Large herbivore subsystem. p. 269-537, In: D.J. Breymeyers and G.M. Van Dyne, eds. Grasslands, Systems Analysis and Man. Cambridge Univ. Press, Cambridge, U.K. 